\title{
Feasibility Establishment With On Board Generated Hydrogen Supplementation and Studies on Emission Characteristics of Gasoline Engine
}

\author{
Saumya Khulbe ${ }^{1}$, Narayan Khatri ${ }^{2}$, P. S Ranjit ${ }^{3}$ \\ ${ }^{l}$ Department of Mechanical Engineering, University of Petroleum and Energy studies, India \\ ${ }^{2}$ Department of Mechanical Engineering, University of Petroleum and Energy studies, India \\ ${ }^{3}$ Department of Mechanical Engineering, University of Petroleum and Energy studies, India
}

Co-Author : Harshit Goyal

University of Petroleum and Energy Studies, P.O. Bidholi Via-Prem Nagar,Dehradun-248007

\begin{abstract}
In present times, the automotive industry is dealing with two major problems. The quest for a substitute fuel that could reduce the burden on currently used petroleum products is one these problems. Secondly, it is the rigorous norms relating to tail pipe emission due to increasing carbon footprints. Worldwide research is being conducted to find a fuel that could solve both these problem simultaneously. The experimental research presented in this paper proposes a step to find one such good fuel.

One of the resources abundantly present on the earth is water. There are many ways in which we can harness energy from it. In this experimental study, electrolysis is used to extract Hydrogen/HHO from distilled water and used as a supplementary fuel to run a 4 stroke SI engine of a motorbike. Subsequently, its feasibility analysis and emission trends have also been studied. The distinguishing feature of this study is that no modifications were required at engine level to carry out this test.

The addition of HHO is known to increase the octane rating of any fuel being currently used in automobiles. This phenomenon leads to more power generation using same amount of fuel thus increasing fuel efficiency. It was found that fuel consumption reduced by almost $25 \%$ depending on the ratio of hydrogen to gasoline being used in combustion chamber. Emission levels were also reduced drastically, amounting to a reduction of $38 \%$ in $\mathrm{HC}$ and approximately $50 \%$ in $N \mathrm{O}_{X}$.
\end{abstract}

Keywords: HHO/Brown's gas, SI Engine, Octane rating

\section{Introduction}

We have come a long way since the first automobile was built. As automobile technology progressed with time, humans' expectations in this sphere increased at the same pace. Today we have reached a stage where we want to run our vehicles on fuel that is readily available, economical and produces almost no emissions which harms the environment. There is worldwide research going on to find a suitable fuel capable of reducing emission and at the same time increasing engine mileage. Various criteria have been developed to compare available fuel candidates which allow ranking them in order of their merits. Among them, one of the sources is Hydrogen which is being implemented for testing in this study.

Hydrogen has certain characteristics which are both unique and desirable. Hydrogen has a gross calorific value of $141790 \mathrm{~kJ} / \mathrm{kg}$ which is much higher when compared to that of gasoline i.e. $47300 \mathrm{~kJ} / \mathrm{kg}$. It has very high flame speed of $265-325 \mathrm{~cm} / \mathrm{sec}$ thus burning faster than gasoline which is only $37-43 \mathrm{~cm} / \mathrm{sec}$. Any addition of Hydrogen to normal fuels will increase rate of combustion and help in extracting more energy from same quantity of fuel. Additionally, it produces no air pollution or greenhouse gases (GHG).It is an environment friendly fuel that has the potential to dramatically reduce tailpipe emissions and our dependence on fossil fuels. Hydrogen can be produced indigenously from several sources thus reducing dependence on petroleum imports.

Hydrogen has great potential to emerge as a supplementary fuel to improve the performance of internal combustion engine. It is a zero emission fuel which uses electrochemical cells or combustion in IC engines to power vehicles and electric devices. It can be also used as a source of energy in ICEs, fuel cells and as an additive to conventional fuels such as gasoline or diesel. The use of hydrogen as an additive offers the hypothesis of enriching the mixture taking advantage of properties from both fuels. One such way of using hydrogen as an additive is being tried in this experimental study.

\section{Methodology}

The principle involved in the studied manner of combustion is to add a small amount of hydrogen gas to the combustion chambers of spark ignition engine. The HHO dry cell produces $\mathrm{HHO} /$ brown's gas by 
electrolysis extracting power from the battery of the vehicle ${ }^{[1]}$.The produced gas passes through a flame arrester making its way to the intake manifold. Here it meets gasoline and air to form a mixture which then goes into the combustion chamber. Exhaust characteristics and fuel mileage is hence studied for the exhaust resulting from above mixture.

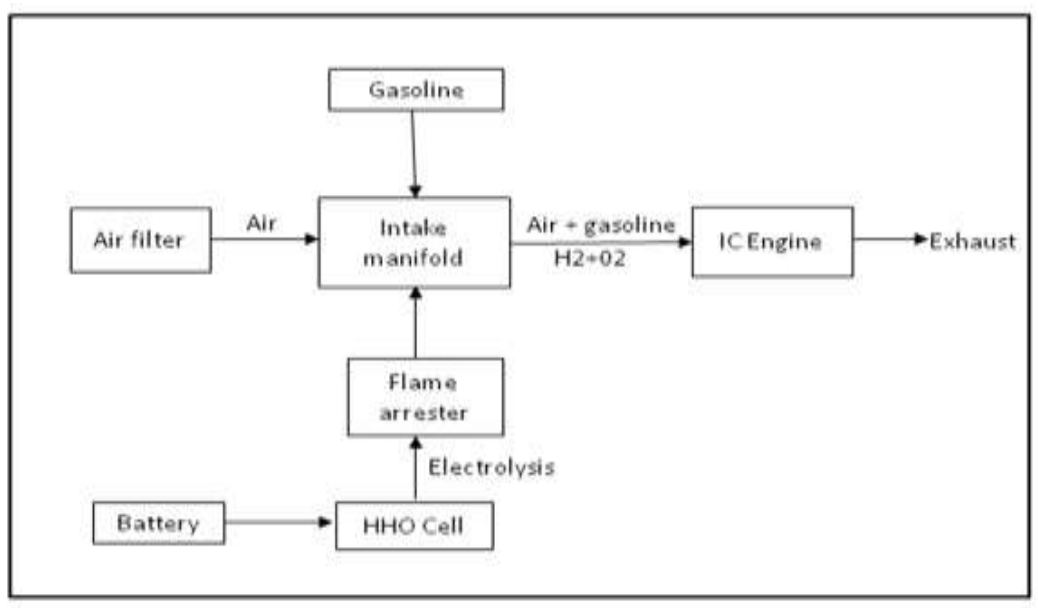

Fig1: Experimental Setup

In this process of hydrogen addition, the combustion rate of gasoline is highly increased, burning entirely and cleaner ${ }^{[2]}$ as hydrogen improves the octane rating of gasoline. Even the formation of unburned hydrocarbons and $\mathrm{NO}_{\mathrm{X}}$ has shown a reduction in values on using hydrogen and gasoline mixture as main fuel. Studies have shown that the addition of hydrogen even in small percentages can greatly reduce hydrocarbon fuel consumption.

The possibility behind this concept is that the presence of hydrogen in fuel mixture can expand the lean operation limit, improve the lean burn ability, and decrease burn duration ${ }^{[3]}$.To apply this method to an engine, a source of hydrogen is required. In present scenario, the merest selection would be to carry a tank filled with hydrogen but it is dangerous to store hydrogen due to its flammability. Therefore, studies are being conducted to design a set up for on board hydrogen generation. One method for doing it can be regeneration of hydrogen from the vehicle's fuel supply or generating hydrogen from electrolysis of water which has been used in this experiment. In the time to come, improved methods can be developed for hydrogen storage on vehicles or methods of on-board hydrogen generation can be studied.

\section{Experimental Setup}

There are many ways in which hydrogen fuel cell can be made. In the methodology adopted in this paper hydrogen is generated from distilled water by process of electrolysis which splits water $\left(\mathrm{H}_{2} \mathrm{O}\right)$ into its component gases, hydrogen, and oxygen. This resultant gas, oxy-hydrogen is commonly known as HHO or Brown's gas or HHO.

The set up consists of two metal plates (Cathode and Anode) immersed in water connected to a current source (battery in this case).Hydrogen is generated by the electrolysis of distilled water using an electrolyte, $\mathrm{NaOH}$. When electricity is passed through the metal plates, hydrogen is liberated at cathode and oxygen is liberated at anode. The volume of hydrogen generated is based upon number of factors such as surface area of plates, number of plates, spacing between the plates, electrolyte; which can always be optimized for increasing the hydrogen generation. Below is an elaborative description of HHO dry cell along with materials used during construction.

\subsection{Construction of Electrode}

The electrodes were made of Stainless steel, mainly because it helps in the generation of Hydrogen .It is an electrically conductive metal which is resistant to corrosion when exposed to electrolyte. Two concentric pipes of stainless steel were put together to make a cell which was responsible to generate Hydrogen. Silicon tubes were applied on the wire wounded around the electrode by the use of glue gun. The silicon also helps to cover the wire completely and prevents any spark which might result in the explosion of the entire kit, as hydrogen is always present at the topmost part of the kit. 


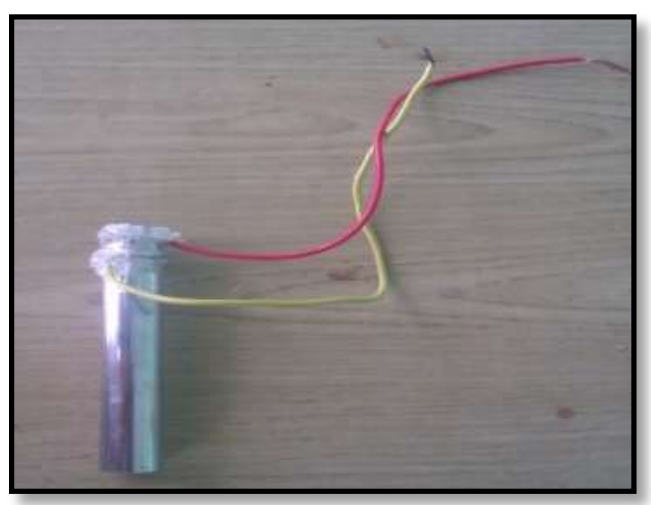

Fig2: Electrode arrangement

The two electrodes should not be in direct contact of each other. So the separation was maintained by placing small bash wood pieces in the gaps between the electrodes. Wood was used as it is a bad conductor of electricity and prevents short-circuiting of the electrodes.

\subsection{Construction of HHO Kit}

The kit was essentially a PVC pipe made air tight by attaching caps at both the ends of the pipe and applying epoxy to make it a sealed chamber to prevent water or hydrogen leakage. Equidistant holes were made from the center to make way for wiring the electrodes. A hole in the center of the cap was made to fit a pneumatic connector.

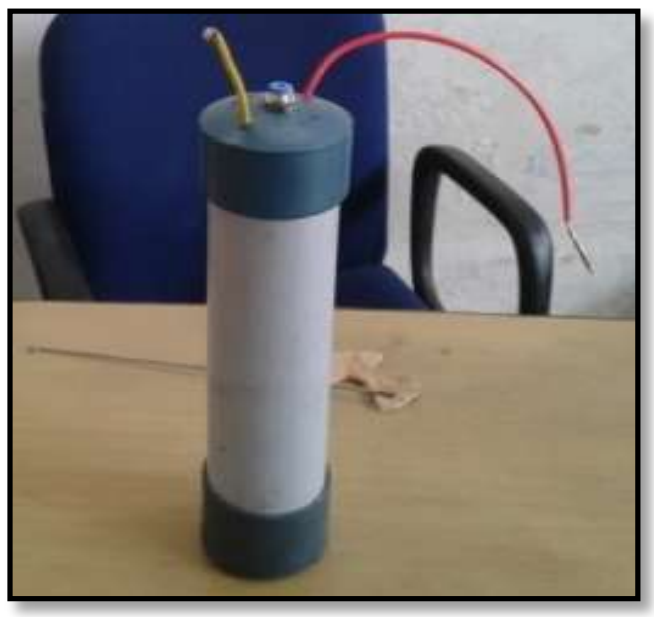

Fig3: HHO cell

A Poly-urethane (PU) pipe was connected to the pneumatic connector which acts as the outlet for the generated hydrogen. This pipe was directed into the air intake pipe of the motorbike which was located just before the bike's carburetor. 


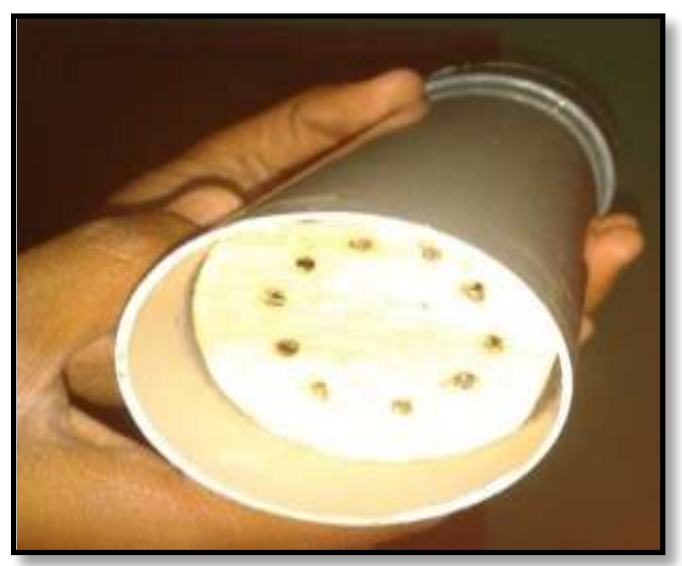

Fig4: Inside section of HHO cell

Inside of the pipe, a bash wood was used in order to provide support to the electrodes inside the container so that they don't move from their position during jerks, if any. The bash wood was coated with epoxy in order to make it water proof.

\subsection{Construction of Flame Arrestor}

Flame Arrestor is a device which restricts the flame from passing through it. It was made up from an Aluminum rod consisting of bubbler stones. Bubbler Stones were put inside the flame arrestor to create fine pores inside it so that the flame occurring as a result of backfiring would be arrested and the supply of hydrogen would not be obstructed. The aluminum rod was fitted with nozzles at both the ends in order to attach piping to the flame arrestor.

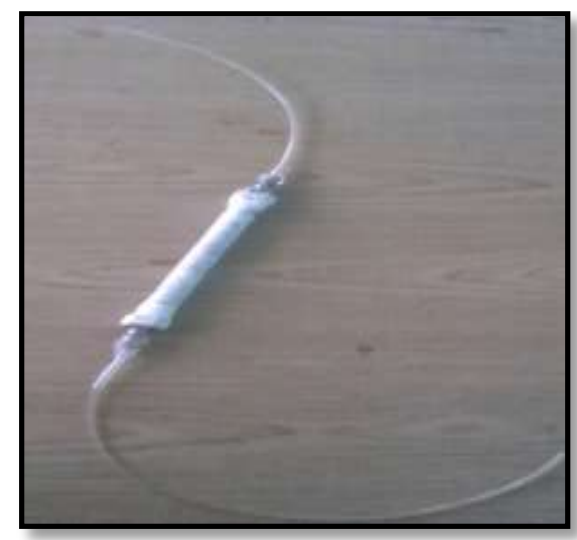

Fig5: Flame arrester

\subsection{Working}

After completing the setup, the wire terminals were connected to a small battery of power rating $12 \mathrm{~V}$ and 5 ampere current. As a result of passage of electricity hydrogen and oxygen bubbles were produced. This setup was connected to bike's battery which is continuously charged by alternator.

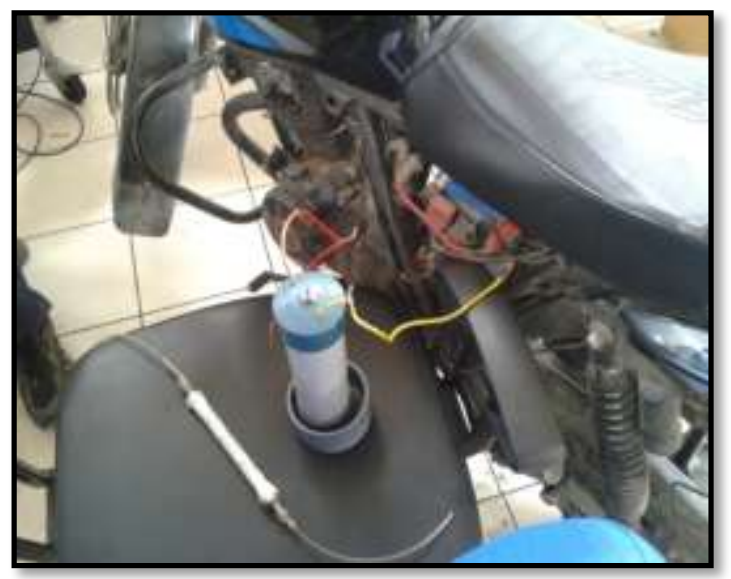




\section{Fig6: HHO cell connected to battery}

The hydroxyl gas or Brown's gas hence generated due to electrolysis in HHO cell was injected into the air intake pipe of the bike by punching a hole in it.

During the entire course of testing the idling screw of the bike was adjusted in such a way that the engine consumes minimum amount of fuel. Emissions as well as fuel consumption readings presented later were taken on this working setup.

\section{Energy Calculations}

$\mathrm{Q}=\mathrm{I} X \mathrm{t}$

$=5 \times 60=300 \mathrm{C}$

In electrolysis half moles of $\mathrm{H}_{2}$ is generated. According to faraday's law, $1 \mathrm{~F}$ of charge deposits $1 \mathrm{gm}$ equivalent (equivalent weight in gm) of any compound.

In electrolysis;

$\mathrm{H}^{+}+\mathrm{e}^{-}=\mathrm{H}(1 \mathrm{gm})=1 / 2 \mathrm{H}_{2}$

$1 \mathrm{~F}$ deposits $1 \mathrm{gm}$ hydrogen

Since $1 \mathrm{~F}=96500 \mathrm{C}$ Therefore

$96500 \mathrm{C}$ charge deposits $1 \mathrm{gm} \mathrm{H}_{2}$

Therefore amount of $\mathrm{H}_{2}$ deposited by $300 \mathrm{C}$ charge $=\frac{1 \times 300}{96500}=0.0031088 \mathrm{gm}$

The amount of $\mathrm{H}_{2}$ liberated:

Amount of $\mathrm{H}_{2}$ generated $=0.0000031088 \mathrm{~kg}$

Calorific value of $\mathrm{H}_{2}=121000 \mathrm{~kJ} / \mathrm{kg}$

Energy released by hydrogen $=\mathrm{m} \times \mathrm{CV}$ of $\mathrm{H}_{2}$

$$
\begin{aligned}
& =0.0000031088 \times 121000 \\
& =0.3761 \mathrm{~kJ}=3761 \mathrm{~J}
\end{aligned}
$$

The amount of $\mathrm{O}_{2}$ liberated:

During electrolysis, $\mathrm{O}^{-2}-2 \mathrm{e}^{-}=\mathrm{O}(16 \mathrm{gm})$

$2 \mathrm{~F}$ deposits $16 \mathrm{gm} \mathrm{O}_{2}$

$1 \mathrm{~F}$ deposits $8 \mathrm{gm} \mathrm{O}_{2}$

96500C deposits $8 \mathrm{gm} \mathrm{O}_{2}$

$300 \mathrm{C}$ will deposit this amount of $\mathrm{O}_{2}=\frac{8 \times 300}{96500}=.099948 \mathrm{gm}$.

Amount of $\mathrm{O}_{2}$ liberated $=.00009948 \mathrm{gm}$

Approximate fuel calculations:

For running $2.25 \mathrm{~min}(145 \mathrm{sec})$, engine requires $5 \mathrm{ml}$ fuel

For running $60 \mathrm{sec}$ fuel required $=\frac{5 \times 60}{145}=2.06 \mathrm{ml}$

Calorific value of gasoline $(\mathrm{LCV})=44400 \mathrm{KJ} / \mathrm{kg}$

$2.06 \mathrm{ml}=2.06 \mathrm{gm}=2.06 / 1000=0.00206 \mathrm{~kg}$

Energy released by fuel in $60 \mathrm{sec}=\mathrm{m} \mathrm{X} \mathrm{CV}$ of fuel

$$
=0.00206 \times 44400=\mathbf{9 1} \mathbf{~ k J}
$$

\section{Results And Findings}

Emission characteristics of the engine were recorded with and without hydrogen addition in order to gather comparative data. The emission testing was performed on the bike with the help of a gas analyzer fitted with a RPM sensor. Initially $\mathrm{HC}, \mathrm{NO}_{\mathrm{X}}$ emissions with only gasoline run engine were recorded by gas analyzer. Later, similar recordings were taken with hydrogen addition. This was done in order to understand noticeable differences in emission parameters by usage of two different kinds of fuel. 


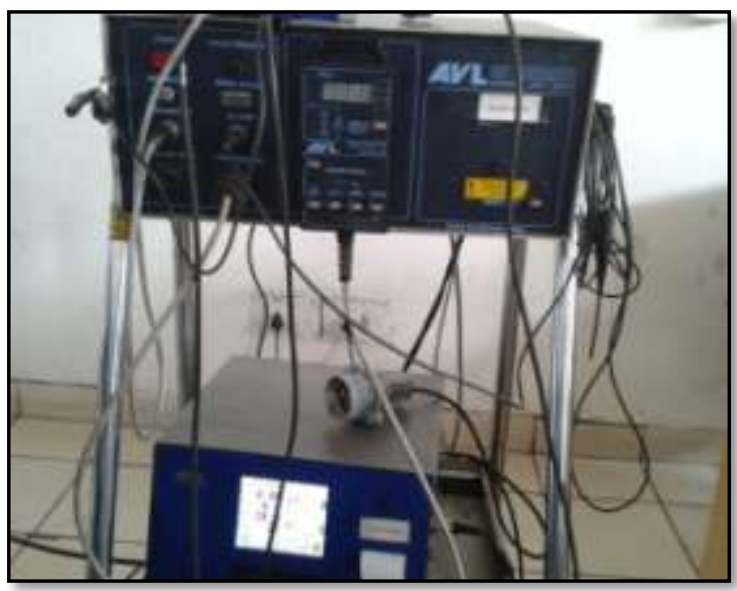

Fig7: Gas analyzer

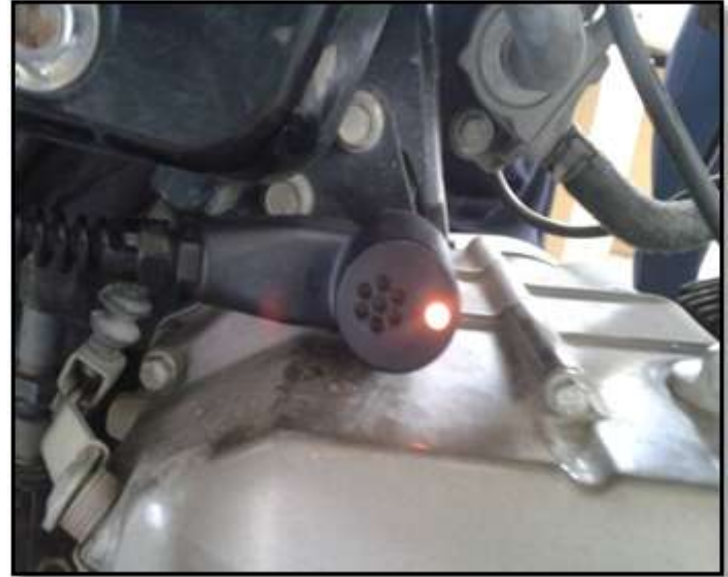

Fig8: RPM sensor

Below are the readings recorded during the experiment:

\begin{tabular}{|l|l|l|l|l|l|l|l|}
\hline \multicolumn{7}{|c|}{ EMISSIONS WITH PURE GASOLINE } \\
\hline S. NO. & $\lambda$ & $\mathrm{CO}(\% \mathrm{vol})$ & $\mathrm{CO}_{2}(\%$ vol $)$ & $\mathrm{O}_{2}(\%$ vol $)$ & $\mathrm{HC}(\mathrm{ppm})$ & $\mathrm{NO}_{\mathrm{X}}(\mathrm{ppm})$ & $\mathrm{RPM}$ \\
\hline 1 & 2.763 & 0.1 & 4.2 & 14.9 & 1777 & 112 & 497 \\
\hline & 2.773 & 0.1 & 4.1 & 14.9 & 1769 & 121 & 543 \\
\hline 2 & 2.828 & 0.1 & 4 & 15.2 & 1868 & 123 & 1006 \\
\hline 3 & 2.85 & 0.1 & 4 & 15.1 & 1761 & 117 & 1006 \\
\hline 4 & 2.902 & 0.1 & 3.9 & 15.3 & 1841 & 141 & 1041 \\
\hline
\end{tabular}

Table 1: Emission levels with pure gasoline

\begin{tabular}{|l|l|l|l|l|l|l|l|}
\hline \multicolumn{7}{|c|}{ EMISSIONS WITH GASOLINE+HYDROGEN } \\
\hline S. NO. & $\lambda$ & $\mathrm{CO}(\% \mathrm{vol})$ & $\mathrm{CO}_{2}(\% \mathrm{vol})$ & $\mathrm{O}_{2}(\% \mathrm{vol})$ & $\mathrm{HC}(\mathrm{ppm})$ & $\mathrm{NO}_{\mathrm{X}}(\mathrm{ppm})$ & $\mathrm{RPM}$ \\
\hline 1 & 2.78 & 0.1 & 4.4 & 14.7 & 1100 & 64 & 820 \\
\hline 2 & 2.694 & 0.11 & 4.7 & 14.2 & 1065 & 63 & 872 \\
\hline 3 & 2.73 & 0.11 & 4.8 & 14.3 & 1032 & 55 & 1005 \\
\hline 4 & 2.629 & 0.12 & 5 & 14.8 & 874 & 45 & 1041 \\
\hline 5 & 2.691 & 0.11 & 4.6 & 14.4 & 1037 & 53 & 1055 \\
\hline 6 & 2.52 & 0.11 & 5 & 13.8 & 1198 & 70 & 1063 \\
\hline 7 & 2.562 & 0.11 & 4.9 & 14 & 1093 & 68 & 1079 \\
\hline
\end{tabular}

Table 2: Emission levels with gasoline + hydrogen

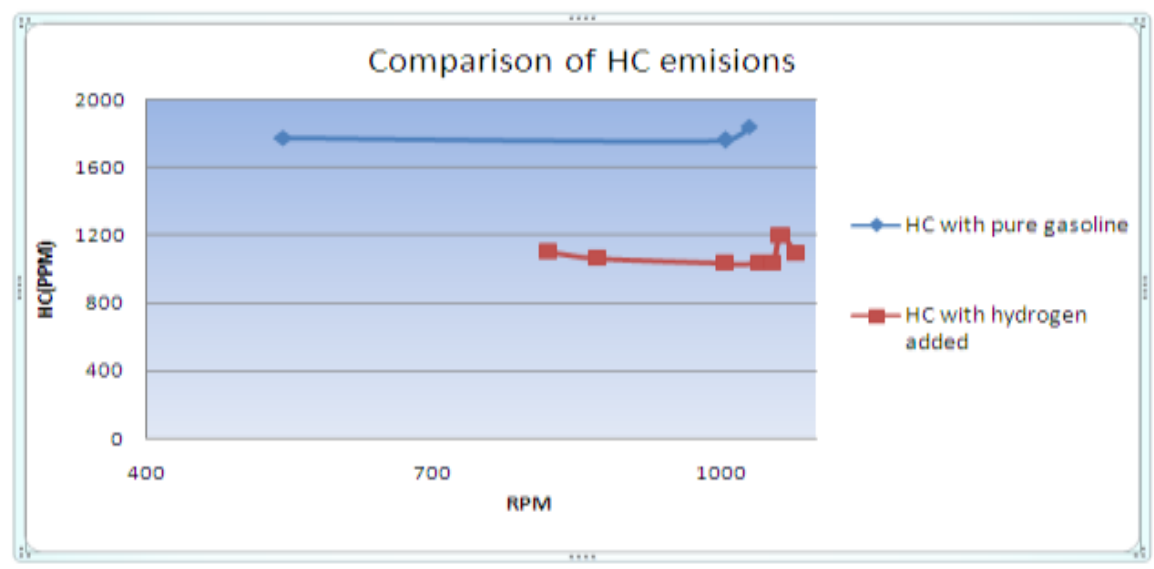

Fig9: HC emission Comparative graph 


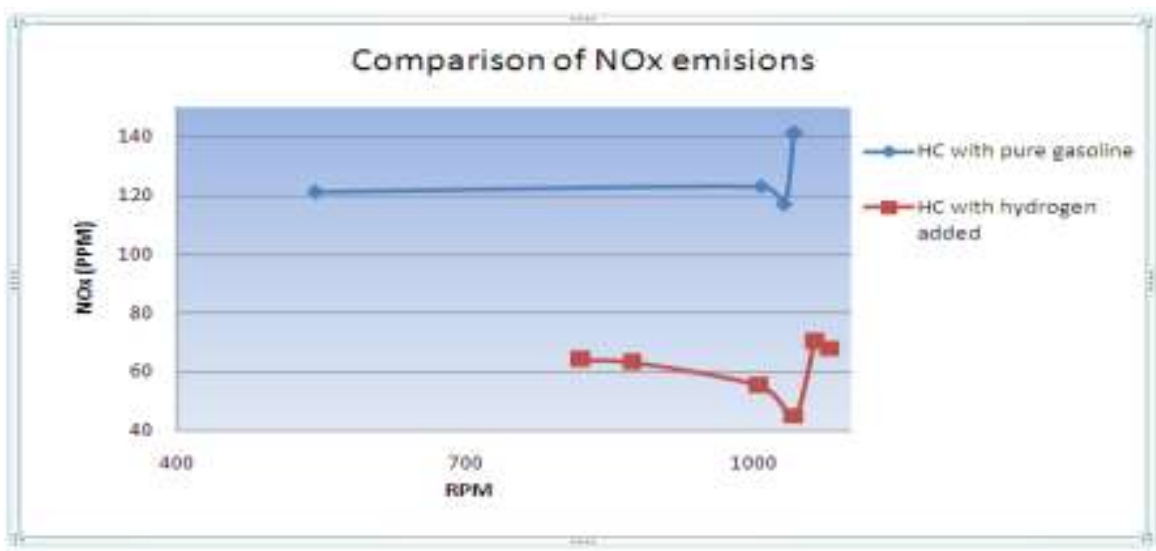

Fig10: $\mathrm{NO}_{\mathrm{x}}$ emission Comparative graph

Above data graphically represents $\mathrm{NO}_{\mathrm{x}}$ and $\mathrm{HC}$ levels at changing engine RPM. From above two graphs the radical reduction in $\mathrm{NO}_{\mathrm{X}}$ and $\mathrm{HC}$ level by use of $\mathrm{HHO}$ as a supplementary fuel is quite evident. Since these values were taken on a running model of motorcycle, no external load application was done on the engine.

In Fig9, it is clearly visible that $\mathrm{HC}$ with pure gasoline was around 1800 PPM which radically came down to 1100PPM on introduction of $\mathrm{HHO}$ to combustion chamber. Similar was the case with $\mathrm{NO}_{\mathrm{X}}$ levels, evident in Fig 10 when compared with an engine running with pure gasoline, $\mathrm{NO}_{\mathrm{X}}$ was around $120 \mathrm{PPM}$ but with introduction of $\mathrm{HHO}$ it came down to around $60 \mathrm{PPM}$.

To sum up there was around 50\% reduction in $\mathrm{NO}_{\mathrm{X}}$ levels over entire range of experimental recordings while $\mathrm{HC}$ reduction was around $38 \%$ after $\mathrm{HHO}$ addition. These kinds of experimental recordings clearly signal towards the great potential of $\mathrm{HHO}$ in emission reduction. The most distinguishing feature of this type of set up is the ease with which it can be used on any engine without any major modification.

\subsection{Fuel Consumption}

\begin{tabular}{|l|l|l|}
\hline S. No. & $\begin{array}{l}\text { Time (in sec) calculated for } \\
\text { consumption of 5ml fuel while sending } \\
\text { only fuel into the inlet manifold }\end{array}$ & $\begin{array}{l}\text { Time calculated (in sec) for } \\
\text { consumption of 5ml fuel while } \\
\text { sending hho and charge(fuel+air) }\end{array}$ \\
\hline 1. & 170 & 228 \\
\hline 2. & 165 & 209 \\
\hline 3. & 170 & 203 \\
\hline 4. & 180 & 225 \\
\hline 5. & 170 & 217 \\
\hline 6. & 168 & 210 \\
\hline 7. & 172 & 223 \\
\hline 8. & 179 & 233 \\
\hline 9. & 171 & 202 \\
\hline 10. & 185 & 208 \\
\hline $\begin{array}{l}\text { Average } \\
\text { time }\end{array}$ & $173 \mathrm{sec}(2.88 \mathrm{~min})$ & $215.8 \mathrm{sec}(3.59 \mathrm{~min})$ \\
\hline
\end{tabular}

$\%$ decrease in fuel consumption $=[(215.8-173) / 173] * 100=\mathbf{2 4 . 7 3} \%$

To collect above mentioned data, an equal amount of gasoline $(5 \mathrm{ml})$ was taken to be sent into inlet of the engine. The procedure was repeated for two cases:

1. With only gasoline as a fuel into inlet

2. Gasoline with HHO introduction into the inlet manifold

Corresponding time taken for fuel consumption in both cases was hence calculated to understand fuel consumption differences. After introduction of $\mathrm{HHO}$ into the inlet manifold fuel consumption was found to be decreased by almost $25 \%$. Thus it clearly shows that addition of hydrogen to a gasoline run engine decreases it fuel consumption, hence increasing the mileage.

\section{Conclusion}

Hydrogen has great potential to do wonders in energy revolution. Being the most common element in the universe hydrogen can be easily extracted from tap water to yield power for vehicles and houses. This experiment was started with a similar idea of utilizing normal water to power IC engines and it brings noticeable difference in emissions and fuel consumption. Slight introduction of distilled water after electrolysis into the combustion chamber drastically improved fuel efficiency of a normal bike engine and brought down the fuel 
consumption by almost $25 \%$.Similar was the effect on emission levels with HC levels decreasing by $38 \%$ while $\mathrm{NO}_{\mathrm{X}}$ by $50 \%$. First traces of $\mathrm{NO}_{\mathrm{X}}$ and $\mathrm{HC}$ were found to be generated at around $800 \mathrm{RPM}$ on adding hydrogen to gasoline while with normal gasoline as a fuel such emission starts at around 400 RPM.

This reduction level clearly indicates the hidden potential of using water (basically hydrogen inside water molecules) as a fuel to run automobiles.

\section{Future Scope}

This experiment can be taken to a higher level of research by finding appropriate ratio of hydrogen to gasoline required to get optimum mileage as well as desired emission levels. New technologies can be developed to generate hydrogen from natural resources. Another area of improvement can be to develop ways in which energy released during this process of hydrogen generation through electrolysis could be increased. High enthalpy is required to break water molecules into hydrogen and oxygen thus energy required to generate hydrogen is comparatively higher than the energy released in the process. But one can always optimize the hydrogen being obtained from this process of electrolysis and find ways to increase efficiency of this process of hydrogen generation. These are the few areas which when focused can help hydrogen in becoming a suitable alternative for currently prevalent petroleum fuels used to run vehicles. The underlying idea is to efficiently consume resources present in nature instead of trying to discover new fuel altogether.

\section{Acknowledgements}

It is with a sense of great satisfaction and pride that we are submitting our research work to International Organization of Scientific Research. First and foremost we sincerely salute our esteemed Institution University of Petroleum \& Energy Studies, Dehradun for giving this wonderful opportunity for conducting this experimental study.

We would like to express our deep sense of gratitude and profound thanks to Department of Mechanical Engineering, UPES Dehradun for its valuable advice, suggestions, insurmountable guidance which played a vital role in carrying out this research work successfully. They were constant beacon of support, without whom, we wouldn't have been able to use the all valuable equipments.

We would also like to thank Mr. Sagar Pavithran, Mr. Nishchay Sukhija, Mr. Harshit Goyal and Ms Sonali Singh for helping towards completion of this study.

\section{References}

[1]. Ali Can Yilmaz, Erinc Uludamar , Kadir Aydin (2010), Effect of hydroxyl (HHO) gas addition on performance and exhaust emissions in compression ignition engines, International Journal of hydrogen energy, volume 35 , issue 20, 11366-11372

[2]. Guidelines for use of hydrogen fuel in commercial vehicles, FMCSA-RRT-07-020, Department of transportation, United States.

[3]. Johz F. Cassidy (1977), Emissions and total energy consumption of a multi-cylinder piston engine running on gasoline and a hydrogen gasoline mixture, National Aeronautics and space administration, Washington.

[4]. Ammar A. Al- Rousan (2010), Reduction of fuel consumption in gasoline engines by introducing HHO gas into intake manifold, International Journal of Hydrogen Energy, 35, 12930-12935.

[5]. Jacob Wall, Effect of hydrogen enriched hydrocarbon combustion on emissions and performance, Department of Biological and Agricultural Engineering, University Of Idaho.

[6]. John F. Cassidy (1977), Emission and total energy consumption of a multi cylinder piston engine running on gasoline and a hydrogen gasoline mixture, NASA, Washington D.C. 